\title{
Association of Sleep Duration and Overweight/Obesity among Children in China
}

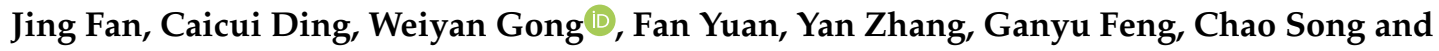 \\ Ailing Liu * \\ Department of Nutrition and Health Education, National Institute for Nutrition and Health, Chinese Center for \\ Disease Control and prevention, Beijing 100050, China; jing_zwtcheroyl@163.com (J.F.); \\ dingcc@ninh.chinacdc.cn (C.D.); gongwy@ninh.chinacdc.cn (W.G.); yuanfan@ninh.chinacdc.cn (F.Y.); \\ zhangyan@ninh.chinacdc.cn (Y.Z.); fenggy@ninh.chinacdc.cn (G.F.); songchao@ninh.chinacdc.cn (C.S.) \\ * Correspondence: liual@ninh.chinacdc.cn; Tel.: +86-10-6623-7059
}

Received: 12 February 2020; Accepted: 13 March 2020; Published: 17 March 2020

\begin{abstract}
To investigate the association of sleep duration with overweight and obesity among children aged 6 to 17 years in China, 2010-2012 data from the China National Nutrition and Health Surveillance (CNHHS) were analyzed. A total of 35,414 children were recruited in the survey. Body mass index (BMI) was converted into three categories: normal weight, overweight and obesity. In multinomial logistic regression model, sleep duration was divided into four groups: very short, short, recommended and long. In restricted cubic splines (RCS), sleep duration was examined as a continuous variable in relation to overweight and obesity. In the very short and short groups, sleep duration was a risk factor for obesity after adjusting for the potential impacts of age, gender, residence, family income, leisure sedentary behavior (SB) and leisure exercise, with OR (Odds Ratio) $=3.01$ (95\% CI (confidence interval): $2.19-4.15$ ) and OR $=1.24$ (95\% CI: 1.14-1.35), respectively. The adjusted OR of overweight for short sleep duration relative to a recommended sleep duration was $1.17(95 \% \mathrm{CI}$ : 1.09-1.26). No significant associations of very short sleep with overweight, of long sleep duration with overweight and obesity were found. The RCS curves between sleep duration and overweight and obesity were both inverted J-shaped. To conclude, the shorter the sleep duration, the higher the risk of overweight and obesity in children. Increasing sleep duration would have a positive effect on reducing overweight and obesity rates in Chinese children.
\end{abstract}

Keywords: sleep duration; overweight; obesity; children; China

\section{Introduction}

Globally, the prevalence of overweight and obesity among children aged 2 to 19 years has increased by 47.1 percent from 1980 to 2013 . The dramatic rise trend over the past few decades is not confined to economically privileged countries (boys: from $16.9 \%$ to $23.8 \%$, girls: from $16.2 \%$ to $22.6 \%$ ), but also increasing rapidly in a growing number of developing countries (boys: from $8.1 \%$ to $12.9 \%$, girls: from $8.4 \%$ to $13.4 \%$ ) [1]. A survey on the physique and health of Chinese students showed that during the nearly 30 years from 1985 to 2014, the prevalence of overweight and obesity among Chinese students aged 7 to 18 years showed a trend of steady increase, from $1.4 \%$ to $12.1 \%, 0.1 \%$ to $7.3 \%$, respectively [2].

Excessive body weight is often positively associated with diabetes, high blood pressure and other chronic diseases [3-5]. The occurrence of these diseases can impose a profound economic burden on the country. In 2010, the combined economic burden of major chronic diseases caused by overweight and obesity in urban and rural China reached 90.77 billion RMB, accounting for 42.9 percent of the economic burden of major chronic diseases [6]. The risk factors for overweight and obesity, such as high energy intake, low fruit and vegetable consumption, less physical activity, genetic factors, have 
always been researched hotspots in many published literatures [7-9]. Recently, attentions have been turned to inadequate sleep, an emerging influential factor $[10,11]$. Sleep is a complex brain process that sustains the body's basic physiological needs [12]. Many countries around the world suffer from people of all ages getting less than the recommended amount of sleep [13]. In 2015, data from a Centers for Disease Control and Prevention(CDC) survey on risky behavior in children and adolescents in the United States showed that $57.8 \%$ of children in grades 6 to 8 and $72.2 \%$ of children in grades 9 to 12 did not get enough sleep while in school [14]. Sleep deprivation has been discussed in previous studies as a possible link to diseases such as obesity, cardiovascular disease, diabetes and malignant tumors $[15,16]$ and experimental studies show that sleep deprivation could lead to weight gain in adults [17]. Sleep deprivation may also be present in Chinese children, while the previous studies on the association of sleep deprivation with overweight/obesity among Chinese children lacked national data [18].

The shape of the curve between sleep duration and overweight/obesity was inconsistent in different studies. In a cross-sectional study involving 66,817 subjects [18], Wu et al. suggested that when sleep duration was maintained at 7-8 hours, the impact on overweight and obesity was the lowest, and lower or higher than the optimal zone would increase the risk of overweight and obesity. The U-shaped relationship was also discussed in earlier epidemiological studies $[19,20]$. A meta-analysis [21] involving 56,584 children showed a moderate negative trend between sleep duration and the risk of overweight and obesity duration. For each additional hour of sleep per day, the risk of being overweight/obese was reduced by $21 \%$. Recently, Zhou et al. [22] evaluated the dose-response relationship between sleep duration and overweight and obesity in a systematic review of prospective cohort studies. The curve was in an inverted J shape, and there was no significant ascending trend after sleep duration surpass 7 to 8 hours. In addition, some epidemiological studies have not found an association between sleep duration and overweight/obesity as well [18,23-26]. Few studies on the association of sleep status with overweight and obesity among nationally representative Chinese children are available. Therefore, the current study used the data from a national representative cross-sectional survey to explore the association of sleep duration with overweight and obesity among Chinese children.

\section{Materials and Methods}

\subsection{Study Participants}

The data were from the China National Nutrition and Health Surveillance (CNHHS) in 2010-2012. The multi-stage stratification and population proportional cluster random sampling method was adopted. All county-level administrative units were divided into four categories: big cities, small and medium-sized cities, ordinary rural areas and poor rural areas. A total of 150 counties (districts) were selected from four categories of areas as study sites. Then proportional sampling approach was adopted to extract six villages or communities at equal intervals from each county/district. Finally, 75 households were randomly selected from each village/community and children aged 6 to 17 years in each family were involved. If the number of children was less than 20 children (10 boys and 10 girls) in each age group in each site, supplementary children would be selected from nearby primary and secondary schools to meet the minimum sample size. Finally, a total of 38,744 children aged 6 to 17 years were investigated [27]. After excluding missing and abnormal data in height, weight, sleep duration and sedentary time, 35414 subjects were included in the study.

An interview-administered questionnaire was used to collect the information about sedentary duration, leisure exercise and sleep duration by trained investigators. The children younger than 10 years old finished the questionnaire with the help of their parents. This study was approved by the ethics review committee of the National Institute for Nutrition and Health, Chinese Center for Disease Control and Prevention (No. 2013-018), and all participants' parents or legal guardian signed the informed consent. 


\subsection{Anthropometric Measurements}

Height and weight were measured for all participants. All measurements were conducted by well-trained investigators under standard operation procedure. The height was measured with an accuracy of $0.1 \mathrm{~cm}$ and the weight was measured with an accuracy of $0.1 \mathrm{~kg}$ [27].

\subsection{Definition of Overweight and Obesity}

Overweight and obesity was classified according to age- and gender-specific BMI cutoff points which developed for Chinese children [28].

\subsection{Categories of Sleep Duration}

The sleep duration was divided into four levels according to the National sleep foundation (NSF) guideline for age-specific sleep recommendations [29]: very short, short, recommended and long sleep duration. For children aged 6 to 13 years, sleep duration $<7 \mathrm{~h} / \mathrm{d}$ was classified as very short, within 7 to $8 \mathrm{~h} / \mathrm{d}$ as short, within 9 to $11 \mathrm{~h} / \mathrm{d}$ as recommended, and more than $11 \mathrm{~h} /$ day as long. For children aged 14 to 17 years, sleep duration $<6 \mathrm{~h} / \mathrm{d}$ was classified as very short, within 6 to $7 \mathrm{~h} / \mathrm{d}$ as short, within 8 to $10 \mathrm{~h} / \mathrm{d}$ as recommended, and more than $10 \mathrm{~h} / \mathrm{d}$ as long.

\subsection{Statistical Analyses}

All data were analyzed using the Statistical Analysis System (SAS) 9.4 software (SAS Institute Inc., Cary, NC, USA). Mean and standard deviation (SD) were used to describe the continuous variables, and the classified variables were presented in the form of frequency and percentage. Differences in demographic characteristics and physical activity among the four sleep groups were examined using one-way analysis of variance (ANOVA) or Chi-square test. Multinomial logistic regression was applied to examine the association of sleep duration with overweight and obesity, where dependent variable was BMI status (normal weight, overweight and obesity), and independent variable was the level of sleep duration (recommended sleep group $=0$, very short sleep group $=1$, short sleep group $=2$, and excessive sleep group $=3$ ). Moreover, gender $($ male $=0$, female $=1)$, age, residence (urban $=0$, rural $=$ 1 ), family income (low income $=0$, middle income $=1$, high income $=2$ ), leisure exercise level (no leisure exercise $=0$, leisure exercise $=1$ ) and leisure sedentary time level (not more than $2 \mathrm{~h} / \mathrm{d}=0$, more than $2 \mathrm{~h} / \mathrm{d}=1$ ) [30] were included in the model as confounders. Additionally, in order to obtain a more objective and realistic correlation in this study, we took sleep duration as a continuous variable and plotted its nonlinear relationship with overweight and obesity using restrictive cubic splines (RCS).

\section{Results}

\subsection{The Distribution of the Characteristics among Different Sleep-Duration Groups.}

The overall proportion of very short, short, recommended, long sleep duration was $0.1 \%, 36.1 \%$, $62.6 \%$ and $0.1 \%$, respectively, among Chinese children aged 6-17 years. Compared with their counterparts, boys, rural residents, those with low family income, with sedentary duration $>2 \mathrm{~h} / \mathrm{d}$ and no leisure exercise had higher proportion of recommended sleep duration. Sleep deprivation was more likely to occur in older children. Among the four sleep groups, significant difference in the rates of overweight and obesity was found, and highest in the very short group (see Table 1).

\subsection{Multivariate Regression Analysis of the Relationship between Sleep Duration and Overweight/Obesity.}

As shown in Table 2, compared with children with recommended sleep duration, those with very short sleep duration and short sleep duration had higher risk of obesity, with adjusted OR (odds ratio) $=3.01$ (95\% CI (confidence interval): 2.19-4.15) and adjusted OR $=1.24$ (95\% CI: 1.14-1.35), respectively. 
Table 1. Demographic characteristics and physical activity of different sleep groups.

\begin{tabular}{|c|c|c|c|c|c|c|}
\hline \multirow{2}{*}{ Variables } & Total & Very Short & Short & Recommended & Long & \multirow{2}{*}{$p$} \\
\hline & $N$ & $N(\%)$ & $N(\%)$ & $N(\%)$ & $N(\%)$ & \\
\hline Total & 35,414 & $308(0.1)$ & $12776(36.1)$ & 22158 (62.6) & $172(0.1)$ & \\
\hline \multicolumn{7}{|l|}{ Gender } \\
\hline Male & 17,859 & $142(46.1)$ & $6334(49.6)$ & 11297 (51.0) & $86(50.0)$ & \multirow[t]{2}{*}{$<0.0001$} \\
\hline Female & 17,555 & $166(53.9)$ & $6442(50.4)$ & $10861(49.0)$ & $86(50.0)$ & \\
\hline Age (years) & 35,414 & $13.23 \pm 3.2$ & $12.31 \pm 3.1$ & $11.56 \pm 3.4$ & $11.66 \pm 3.4$ & $<0.0001$ \\
\hline \multicolumn{7}{|l|}{ Region } \\
\hline Urban & 17,826 & $211(68.5)$ & 6589(51.6) & $10940(49.4)$ & $86(50.0)$ & \multirow[t]{2}{*}{$<0.0001$} \\
\hline Rural & 17,588 & $97(31.5)$ & 6187(48.4) & 11218(50.6) & $86(50.0)$ & \\
\hline \multicolumn{7}{|l|}{ Family income } \\
\hline Low income & 22,298 & $185(60.1)$ & $7940(62.2)$ & $14,065(63.5)$ & $108(62.8)$ & \multirow[t]{4}{*}{$<0.0001$} \\
\hline Middle income & 4267 & 49 (15.9) & $1682(13.2)$ & $2520(11.4)$ & $16(9.3)$ & \\
\hline High income & 1119 & $24(7.8)$ & $395(3.1)$ & $691(3.1)$ & $9(5.2)$ & \\
\hline Unknown & 7730 & $50(16.2)$ & 2759 (21.6) & $4882(22.0)$ & 39 (22.7) & \\
\hline \multicolumn{7}{|l|}{ Leisure exercise } \\
\hline No & 22,088 & $160(52.0)$ & 8001 (62.6) & $13,852(62.5)$ & 75 (43.6) & \multirow[t]{2}{*}{$<0.0001$} \\
\hline Yes & 13,326 & $148(48.1)$ & 4775 (37.4) & $8306(37.5)$ & $97(56.4)$ & \\
\hline \multicolumn{7}{|l|}{ Leisure SB } \\
\hline$\leq 2 \mathrm{~h} / \mathrm{d}$ & 14,241 & $68(22.1)$ & 4539 (35.5) & 9546 (43.1) & 88 (51.2) & \multirow[t]{2}{*}{$<0.0001$} \\
\hline$>2 \mathrm{~h} / \mathrm{d}$ & 21,173 & $240(77.9)$ & 8237 (64.5) & $12,612(56.9)$ & $84(48.8)$ & \\
\hline \multicolumn{7}{|l|}{ BMI status } \\
\hline Obesity & 2779 & $52(16.9)$ & $1028(8.1)$ & $1687(7.6)$ & $12(7.0)$ & \multirow[t]{3}{*}{$<0.0001$} \\
\hline Overweight & 3736 & $36(11.7)$ & 1443 (11.3) & $2246(10.1)$ & $11(6.4)$ & \\
\hline Normal & 28,899 & $220(71.4)$ & $10,305(80.7)$ & $18,225(82.3)$ & $149(86.6)$ & \\
\hline
\end{tabular}

Table 2. Multivariate logistic regression analysis of sleep duration and overweight and obesity.

\begin{tabular}{|c|c|c|}
\hline \multirow{2}{*}{ Variables } & Overweight & Obesity \\
\hline & Odds Ratio (95\% CI (Confidence Interval)) & OR $(95 \%$ CI) \\
\hline \multicolumn{3}{|l|}{ Sleep duration } \\
\hline Very short & $1.34(0.94-3.01)$ & $3.01(2.19-4.15)$ \\
\hline Short & $1.17(1.09-1.26)$ & $1.24(1.14-1.35)$ \\
\hline Recommended & reference & reference \\
\hline Long & $0.58(0.32-1.08)$ & $0.83(0.46-1.51)$ \\
\hline \multicolumn{3}{|l|}{ Gender } \\
\hline Male & reference & reference \\
\hline Female & $0.69(0.64-0.73)$ & $0.57(0.52-0.61)$ \\
\hline Age & $0.95(0.94-0.96)$ & $0.85(0.84-0.86)$ \\
\hline \multicolumn{3}{|l|}{ Residence } \\
\hline Urban & reference & reference \\
\hline Rural & $0.69(0.64-0.74)$ & $0.62(0.57-0.68)$ \\
\hline \multicolumn{3}{|l|}{ Family income } \\
\hline Low income & reference & reference \\
\hline Middle income & $1.22(1.10-1.35)$ & $1.30(1.16-1.46)$ \\
\hline High income & $1.20(1.20-1.44)$ & $1.29(1.06-1.58)$ \\
\hline \multicolumn{3}{|l|}{ Leisure exercise } \\
\hline No & reference & reference \\
\hline Yes & $1.16(1.08-1.25)$ & $1.27(1.17-1.38)$ \\
\hline \multicolumn{3}{|c|}{ Leisure sedentary behavior } \\
\hline$\leq 2 \mathrm{~h} / \mathrm{d}$ & reference & reference \\
\hline$>2 \mathrm{~h} / \mathrm{d}$ & $1.10(1.02-1.18)$ & $1.10(1.01-1.19)$ \\
\hline
\end{tabular}


Those with short sleep duration had a higher risk of overweight (adjusted ORs $=1.17,95 \%$ CI: 1.09-1.26). No significant relationship was found between long sleep duration and overweight and obesity. In addition, the risk of overweight and obesity was higher among younger children, boys, urban children, those with sedentary duration $>2 \mathrm{~h} / \mathrm{d}$, those doing leisure exercise, and those with higher family income.

\subsection{Restrictive Cubic Splines Demonstrate the Relationship between Sleep Duration and the Risk of Overweight/Obesity.}

The quantiles of cumulative sleep time (25th, 50th, and 75th percentiles) were selected as knots for plotting the RCS curve, fitting the spline function piecewise and smoothing the connection at the break point, as shown in Figure 1. The corresponding ORs and 95\% CI of the duration of sleep at the integral point in the curve with $8.5 \mathrm{~h} / \mathrm{d}$ as reference were listed in Table 3 . The number of children sleeping more than $12.0 \mathrm{~h} / \mathrm{d}$ was too small, so the corresponding ORs were not listed. Overall, both the curve for overweight and obesity were inverted J shaped trend. With the increase of sleep duration, the risks of overweight and obesity decreased. Compared with children with $8.5 \mathrm{~h} / \mathrm{d}$ sleep, children with 4.0/d sleep had a higher risk for overweight $(\mathrm{OR}=1.88,95 \% \mathrm{CI}: 1.40-2.54)$ and obesity $(\mathrm{OR}=2.55,95 \% \mathrm{CI}$ : 1.78-3.65).

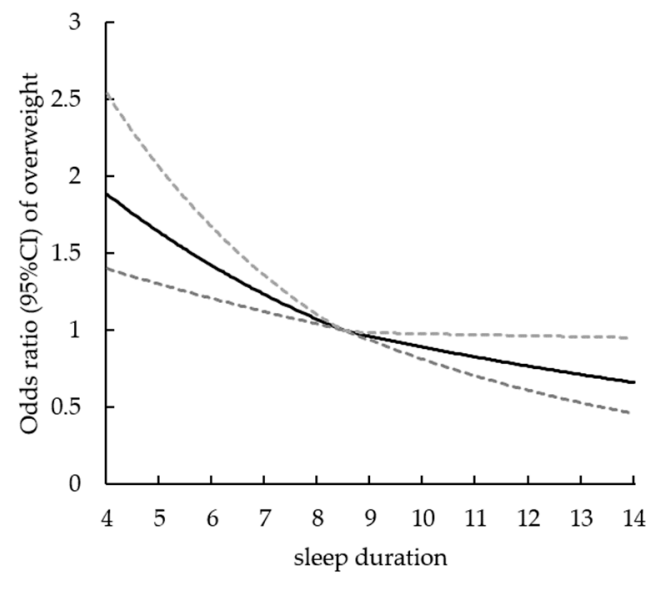

A

Figure 1. Non-linear regression curves of associations of sleep duration with overweight (A) and obesity (B).

Table 3. OR and 95\% CI for the restrictive cubic splines RCS.

\begin{tabular}{ccc}
\hline Sleep Duration (h/d) & Overweight & Obesity \\
\hline 4.0 & $1.88(1.40-2.54)$ & $2.55(1.78-3.65)$ \\
5.0 & $1.63(1.30-2.06)$ & $2.07(1.57-2.73)$ \\
6.0 & $1.42(1.21-1.67)$ & $1.68(1.38-2.04)$ \\
7.0 & $1.23(1.12-1.35)$ & $1.36(1.21-1.52)$ \\
8.0 & $1.07(1.04-1.10)$ & $1.10(1.07-1.14)$ \\
9.0 & $0.96(0.93-0.98)$ & $0.93(0.90-0.96)$ \\
10.0 & $0.89(0.81-0.98)$ & $0.81(0.73-0.90)$ \\
11.0 & $0.82(0.70-0.97)$ & $0.71(0.59-0.85)$ \\
12.0 & $0.77(0.61-0.96)$ & $0.62(0.48-0.80)$ \\
\hline
\end{tabular}

\section{Discussion}

The current study explored that Chinese children who slept less than the recommended range were more likely to be overweight and obese by both RCS and multivariate logistic analysis. With the increase of sleep duration, the risk of overweight and obesity gradually decreased. In terms of how sleep deprivation affects weight, Data et al. [31] found the positive relationships between sleep 
deprivation and blood glucose fluctuations, negative mood, and cravings in an n-of- 1 randomized pilot study. The association of sleep deprivation with blood glucose fluctuations also showed a similar trend in a review [32]. These consequences contribute to high calorie intake, which leads to obesity. Moreover, sleep deprivation may result in metabolic disorders like abnormal leptin levels, which can also lead to obesity [33].

The results of the current study are consistent with those of previous studies [34-36], which showed an inverse relationship between the risk of overweight and obesity and sleep duration. While the trend of RCS curves in this study is not consistent with h conclusions of Wu et al. [18]. They recruited 66,817 school-age children in Guangzhou Province and plotted cubic splines based on their personal characteristics and sleep duration. The risk of being overweight and obese was lowest within a certain period $(7-8 \mathrm{~h} / \mathrm{d})$, and both insufficient sleep and excessive sleep outside that period increase the risk. This U-shaped curve relationship has also been revealed in another studies [37]. However, in our study, we did not observe an increase trend in overweight/obesity rates associated with excessive sleep duration. This may be due to the different distribution of participants in different sleep groups. The number of children in our study who got more than the recommended amount of sleep was extremely small. Therefore, the relationship between excess sleep duration and overweight and obesity may be influenced. In fact, a negative relationship between sleep duration and BMI was found in a number of pediatric cross-sectional and longitudinal studies [38-42], and U-shaped curves were often pointed out in adults $[43,44]$. Marshall et al. argued that because of the ceiling effect, few children sleep excessively long in their daily lives [45]. Currently, there are many studies on the relationship between sleep restriction and overweight and obesity in adults and children, but the effect of excessive sleep duration on body weight is not well understood. The information from Chinese population will be helpful. In our study, all respondents were recruited from the CNHHS, a survey covered 31 provinces, autonomous regions and province-level municipality in China, which can provide more information for the understanding of this area. In our study, consistent with previous findings, girls, older children, and rural children had lower risk of overweight and obesity [30-32]. Children doing leisure exercise were found to have a higher rate of overweight and obesity than those without leisure exercise in the current study. This may be related to the fact that most Chinese children paid attention to their weight [34], and those who were dissatisfied with their weight were more likely to conduct weigh loss behaviors, including participating in exercise [46]. It is also possible that the children who did leisure exercise had higher muscle mass, which made them heavier and thus wrongly classified as overweight or obese.

Our study had some limitations that need to be addressed in any future work. Firstly, this national survey was cross-sectional, thus, the directionality of the causation cannot be established. Further prospective cohort studies are warranted if permitted. Secondly, energy intake was not taken into consideration in the study, and high energy-dense eating habits plays an important role in weight gain. In addition, the sleep duration in the study was self-reported, which may differ from the actual sleep duration.

\section{Conclusions}

The prevalence of overweight and obesity among Chinese children may be linked to inadequate sleep duration. With the increase of sleep duration, the risk of overweight and obesity gradually decreased, and the trend gradually leveled off. The overall curve presented an inverted J-shape. Ensuring adequate sleep duration for children is of great significance in controlling overweight and obesity in children and healthy lifestyle education should be conducted for children to contain the rapid increase of overweight and obesity for Chinese children.

Author Contributions: Formal analysis, J.F.; Methodology, J.F. and A.L.; project administration, A.L.; Supervision, A.L.; Writing—original draft, J.F.; Writing—review \& editing, F.Y., G.F., Y.Z., C.D., C.S.; W.G. and A.L. All authors have read and agreed to the published version of the manuscript. 
Funding: This research was funded by the Major program for health care reform from National Health Commission of the People's Republic of China grant number (20120212).

Acknowledgments: We would like to thank all the participants in our study and all the staff working for the China National Nutrition and Health Survey in 2010-2012.

Conflicts of Interest: The authors declare no conflict of interest.

\section{References}

1. Ng, M.; Fleming, T.; Robinson, M.; Blake, T.; Nicholas, G.; Christopher, M.; Mullany, E.C.; Stan, B.; Cristiana, A.; Abera Semaw, F.; et al. Global, regional, and national prevalence of overweight and obesity in children and adults during 1980-2013: A systematic analysis for the Global Bur den of Disease Study 2013. Lancet 2014, 384, 766-781. [CrossRef]

2. Wang, S.; Dong, Y.H.; Wang, Z.H.; Zou, Z.Y.; Ma, J. Trends in overweight and obesity among Chinese children of 7-18 years old during 1985-2014. CPMA 2017, 51, 300-305. [CrossRef]

3. Global Strategy on Diet, Physical Activity and Health. Available online: https://www.who.int/ dietphysicalactivity/childhood/en/ (accessed on 27 January 2020).

4. Re, R.N. Obesity-related hypertension. Ochsner. J. 2009, 9, 133-136.

5. Mitchell, A.B.; Cole, J.W.; McArdle, P.F.; Cheng, Y.-C.; Ryan, K.A.; Sparks, M.J.; Mitchell Braxton, D.; Kittner Steven, J. Obesity increases risk of ischemic stroke in young adults. Stroke 2015, 46, 1690-1692. [CrossRef]

6. Zhang, J.; Shi, X.M.; Liang, X.F. Economic costs of both overweight and obesity among Chinese urban and rural residents, in 2010. Chin. J. Epi. 2013, 34, 598-600. [CrossRef]

7. Stone, S.; Abkevich, V.; Russell, D.L.; Riley, R.; Timms, K.; Tran, T.; Trem, D.; Frank, D.; Jammulapati, S.; Neff, C.D.; et al. TBC1D1 is a candidate for a severe obesity gene and evidence for a gene/gene interaction in obesity predisposition. Hum. Mol. Genet. 2006, 15, 2709-2720. [CrossRef] [PubMed]

8. Otang-Mbeng, W.; Otunola, G.A.; Afolayan, A. Lifestyle factors and co-morbidities associated with obesity and overweight in Nkonkobe Municipality of the Eastern Cape, South Africa. J. Health PopulNutr. 2017, 36, 22. [CrossRef]

9. Hruby, A.; Manson, J.E.; Qi, L.; Malik, V.S.; Rimm, E.B.; Sun, Q.; Willett, W.C.; Hu, F.B. Determinants and Consequences of Obesity. Am. J. Public Health 2016, 106, 1656-1662. [CrossRef]

10. Chanut, J.P.; Dutil, C. Lack of sleep as a contributor to obesity in adolescents: Impacts on eating and activity behaviors. Int. J. Behave Nutr. Phys. Act 2016, 13, 103. [CrossRef]

11. Sea, S.H.; Shim, Y.S. Association of Sleep Duration with Obesity and Cardiometabolic Risk Factors in Children and Adolescents: A Population-Based Study. Sci. Rep. 2019, 9, 9463. [CrossRef]

12. Rosenblatt, L.; van Swinderen, B. The yin and yang of sleep and attention. Trends Neuro. sci. 2015, 38, 776-786.

13. Hafner, M.; Stepanek, M.; Taylor, J.; Troxel, W.M.; Van Stolk, C. Why Sleep Matters-The Economic Costs of Insufficient Sleep: A Cross-Country Comparative Analysis. Rand Health $Q$ 2017, 6, 11. [PubMed]

14. Wheaton, A.G.; Jones, S.E.; Cooper, A.C.; Croft, J.B. Short sleep duration among middle school and high school students-United States, 2015. Morb. Mortal Wkly Rep. 2018, 67, 85-90. [CrossRef] [PubMed]

15. Chaput, J.P. Is sleep deprivation a contributor to obesity in children? Eat Weight Disord. 2016, $21,5-11$. [CrossRef]

16. Kochanek, K.D.; Murphy, S.L.; Xu, J.; Arias, E. Mortality in the United States, 2013. NCHS Data Brief S 2014, 178, 1-8.

17. Spaeth, A.M.; Dinges, D.F.; Goel, N. Effects of experimental sleep restriction on weight gain, caloric intake, and meal timing in healthy adults. Sleep 2013, 36, 981-990. [CrossRef]

18. Wu, J.; Wu, H.; Wang, J.; Guo, L.; Deng, X.; Lu, C. Associations between Sleep Duration and Overweight/Obesity: Results from 66,817 Chinese Adolescents. Sci. Rep. 2015, 5, 16686. [CrossRef]

19. Patel, S.R.; Malhotra, A.; White, D.P.; Gottlieb, D.J.; Hu, F.B. Association between reduced sleep and weight gain in women. Am. J. Epidemiol. 2006, 164, 947-954. [CrossRef]

20. Kobayashi, D.; Takahashi, O.; Shimbo, T.; Okubo, T.; Arioka, H.; Fukui, T. High sleep duration variability is an independent risk factor for weight gain. Sleep Breath 2013, 17, 167-172. [CrossRef]

21. Runa, H.; Xin, P.; Cai, W.; He, K.; Tang, Q. Habitual Sleep Duration and Risk of Childhood Obesity: Systematic Review and Dose-response Meta-analysis of Prospective Cohort Studies. Sci. Rep. 2015, 5, 16160. [CrossRef] 
22. Zhou, Q.; Zhang, M.; Hu, D. Dose-response association between sleep duration and obesity risk: A systematic review and meta-analysis of prospective cohort studies. Sleep Breath 2019, 23, 1035-1045. [CrossRef]

23. Bjorklund, C.; Bondyr-Carlsson, D.; Lapidus, L.; Lissner, L.; Maansson, J.; Skoog, I.; Bengtsson, C. Sleep disturbances in midlife unrelated to 32-year diabetes incidence: The prospective population study of women in Gothenburg. Diabetes Care 2005, 28, 2739-2744. [CrossRef] [PubMed]

24. Strangest, S.; Cappuccio, F.P.; Kandala, N.; Miller, M.A.; Taggart, F.M.; Kumari, M.; Ferrie, J.E.; Shipley, M.J.; Brunner, E.J.; Marmot, M.G. Cross-sectional versus prospective associations of sleep duration with changes in relative weight and body fat distribution: The Whitehall II Study. Am. J. Epidemiol. 2008, 167, 321-329. [CrossRef] [PubMed]

25. Nagai, M.; Tomato, Y.; Watanabe, T.; Kakizaki, M.; Tsuji, I. Association between sleep duration, weight gain, and obesity for long period. Sleep Med. 2013, 14, 206-210. [CrossRef] [PubMed]

26. Nishiura, C.; Hashimoto, H. Sleep duration and weight gain: Reconsideration by panel data analysis. $J$. Epidemiol. 2014, 24, 404-409. [CrossRef]

27. Zhao, L.J.; Ma, G.S.; Piao, J.; Zhang, J.; Dongmei, Y.U.; Yuna, H.E.; Huo, J.; Xiaoqi, H.U.; Yang, Z.; Yang, X. Scheme of the 2010-2012 Chinese nutrition and health surveillance. Chin. J. Prep. Med. 2016, 50, $204-207$. [CrossRef]

28. Group of China Obesity Task Force Correspondence. Body mass index reference norm for screening overweight and obesity in Chinese children and adolescents. Chin. J. Epi. 2004, 25, 97-102.

29. National Sleep Foundation Recommends New Sleep Times. Available online: https://www.sleepfoundation. org/press-release/national-sleep-foundation-recommends-new-sleep-times. (accessed on 27 January 2020).

30. Bureau of disease control and prevention, ministry of health, PRC. Guidelines for the Prevention and Control of Overweight and Obesity among School-Age Children in China; People's Medical Publishing House: Beijing, China, 2007; Volume 6, ISBN 9787117096034.

31. Daza, E.J.; Wac, K.; Oppezzo, M. Effects of Sleep Deprivation on Blood Glucose, Food Cravings, and Affect in a Non-Diabetic: An N-of-1 Randomized Pilot Study. Healthcare 2019, 8, 6. [CrossRef]

32. Arora, T.; Taheri, S. Sleep Optimization and Diabetes Control: A Review of the Literature. Diabetes Ther. 2015, 6, 425-468. [CrossRef]

33. Chaput, J.P.; Després, J.P.; Bouchard, C.; Tremblay, A.; Tremblay, A. Short sleep duration is associated with reduced leptin levels and increased adiposity: Results from the Quebec family study. Obesity (Silver Spring) 2007, 15, 253-261. [CrossRef]

34. Nan, H.; Hu, X.Q. Obesity related knowledge, attitude and practice of primary students in six cities of China. Chongqing Med. J. 2011, 2, 238-241.

35. Li, L.; Zhang, S.; Huang, Y.; Chen, K. Sleep duration and obesity in children: A systematic review and meta-analysis of prospective cohort studies. J. Paediatr. Child Health 2017, 53, 378-385. [CrossRef]

36. Wu, G.B. Analysis of the correlation between sleep and overweight and obesity in middle school students in Urumqi, China. Chin. J. Child Health Care 2018, 12, 1346-1349.

37. Sivertsen, B.; Pallesen, S.; Sivertsen, B.; Pallesen, S.; Sand, L.; Hysing, M. Sleep and body mass index in adolescence: Results from a large population-based study of Norwegian adolescents aged 16 to 19 years. BMC Pediatr. 2014, 14, 204. [CrossRef]

38. Danielsen, Y.S.; Pallesen, S.; Stormark, K.M.; Nordhus, I.H.; Bjorvatn, B. The relationship between school day sleep duration and body mass index in Norwegian children (aged 10-12). Int. J. Pediatr. Obes 2010, 5 , 214-220. [CrossRef] [PubMed]

39. Gupta, N.K.; Mueller, W.H.; Chan, W.; Meininger, J.C. Is obesity associated with poor sleep quality in adolescents? Am. J. Hum. Biol. 2002, 14, 762-768. [CrossRef] [PubMed]

40. Sekine, M.; Yamagami, T.; Handa, K.; Saito, T.; Nanri, S.; Kawaminami, K.; Tokui, N.; Yoshida, K.; Kagamimori, S. A dose-response relationship between short sleeping hours and childhood obesity: Results of the Toyama birth cohort study. Child Care Health Dev. 2002, 28, 163-170. [CrossRef]

41. Von Kries, R.; Toschke, A.; Wurmser, H.; Sauerwald, T.; Koletzko, B. Reduced risk for overweight and obesity in 5- and 6-y-old children by duration of sleep-A cross-sectional study. Int. J. Obes 2002, 26, 710-716. [CrossRef]

42. Eisenmann, J.C.; Ekkekakis, P.; Holmes, M. Sleep duration and overweight among Australian children and adolescents. Acta Paediatr. 2006, 95, 956-963. [CrossRef] 
43. Singh, M.; Drake, C.; Roehrs, T.; Roehrs, T.; Hudgel, D.W.; Roth, A.T. The association between obesity and short sleep duration: a population-based study. J Clin Sleep Med. 2005, 1, 357-363. [CrossRef]

44. Taheri, S.; Lin, L.; Austin, D.; Young, T.; Mignot, E. Short sleep duration is associated with reduced leptin, elevated ghrelin, and increased body mass index. PLoS Med. 2004, 1, e62. [CrossRef] [PubMed]

45. Marshall, N.S.; Glozier, N.; Grunstein, R.R. Is sleep duration related to obesity? A critical review of the epidemiological evidence. Sleep Med. Rev. 2008, 12, 289-298. [CrossRef] [PubMed]

46. Lu, C.; Wang, Z.H.; Dong, Y.; Ma, J. Prevalence of weight-loss behaviors and the associations between weight-loss behaviors and weight-related perceptions among students in primary and middle schools in China. Chin. J. Sch. Health 2017, 3, 330-333.

(C) 2020 by the authors. Licensee MDPI, Basel, Switzerland. This article is an open access article distributed under the terms and conditions of the Creative Commons Attribution (CC BY) license (http://creativecommons.org/licenses/by/4.0/). 